\title{
Autoantibodies to the Heat-Shock Protein hsp90 in Systemic Lupus Erythematosus
}

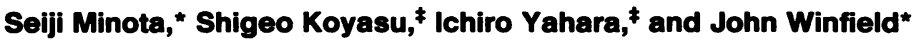 \\ ${ }^{*}$ Division of Rheumatology and Immunology, University of North Carolina, Chapel Hill, North Carolina 27514; and ${ }^{\ddagger}$ Department of \\ Cell Biology, The Tokyo Metropolitan Institute of Medical Science, Tokyo, Japan
}

\begin{abstract}
Patients with systemic lupus erythematosus (SLE) develop multiple autoantibodies to self-antigens. Analysis of autoantibody systems in this and related autoimmune disorders can provide information of etiologic and pathogenetic significance. We report here a previously unrecognized autoantibody to the 90,000-D heat-shock protein, hsp90, a molecule thought to have important functions in the cellular response to stress, virus-induced transformation, steroid hormone receptor action, and cellular activation. Autoantibodies to hsp90 were exclusively of the IgG class, and were detected in $\sim 50 \%$ of unselected patients with SLE and 2/6 patients with idiopathic polymyositis. Anti-hsp90 antibodies were not detected in sera from 10 normal subjects, 10 patients with rheumatoid arthritis, or 7 patients with scleroderma. The identity of this major intracytoplasmic antigen was established by its specific removal from nonionic detergent cell lysates following immunoabsorption with monospecific rabbit anti-hsp90, and by demonstration of increased synthesis following a 10 -min $45^{\circ} \mathrm{C}$ heat shock. These data define the frequent occurrence of a novel autoantibody to a major heat-shock protein in patients with SLE.
\end{abstract}

\section{Introduction}

A central feature of systemic lupus erythematosus (SLE) is the development of autoantibodies to multiple self-constituents. Several autoantibodies in this disorder, i.e., those to doublestranded DNA and to the nuclear antigen, Sm, are essentially disease-specific (1), and their presence in patient serum is of important diagnostic utility. Others, such as those directed to surface membrane determinants on lymphocytes, contribute substantially to the $\mathrm{T}$ cell depletion and immunoregulatory dysfunction characteristic of patients with active SLE (reviewed in 2).

We report here a hitherto unrecognized IgG autoantibody in $\sim 50 \%$ of unselected patients with SLE to a $90-\mathrm{kD}$ heatshock protein, hsp $90^{1}(3,4)$. The exact function(s) of heatshock proteins (5) is unknown, but recent evidence that hsp90 forms stable complexes in the cells with certain virus-encoded transforming proteins $(6,7)$, steroid receptors $(8)$, and F-actin $(3,4)$ raises the possibility that autoantibodies to this antigen

Address reprint requests to Dr. Winfield, Division of Rheumatology and Immunology, 932 FLOB $231 \mathrm{H}$, UNC-CH, Chapel Hill, NC 27514.

Received for publication 15 June 1987 and in revised form $17 \mathrm{Au}$ gust 1987.

1. Abbreviations used in this paper: hsp90, 90-kD heat shock protein.

J. Clin. Invest.

(c) The American Society for Clinical Investigation, Inc. 0021-9738/88/01/0106/04 \$2.00

Volume 81, January 1988, 106-109 could exert important effects on the biology of the cell in this disorder. In addition, because molecular mimicry (epitope homology) between microbial antigens and self-proteins may underlie autoantibody formation in autoimmune and infectious diseases $(9,10)$, etiologic information with respect to putative viral "triggers" of SLE may derive from the present observations as well.

\section{Methods}

Patients and serum. Venous blood was obtained from patients attending the University of North Carolina Lupus Clinic who met the American Rheumatism Association revised criteria for classification as SLE (11), and from 10 normal subjects. After separation from blood, serum was aliquoted and stored at $-70^{\circ} \mathrm{C}$. Each serum aliquot was heated at $56^{\circ} \mathrm{C}$ for $1 \mathrm{~h}$ immediately before use to inactivate C. For certain experiments, serum was ultracentrifuged at $105,000 \mathrm{~g}$ for $2 \mathrm{~h}$ at $4^{\circ} \mathrm{C}$ to remove Clq-binding immune complexes and IgG aggregates (12).

Lymphocytes. Normal human peripheral blood mononuclear cells (PBMC) were separated from heparinized blood by flotation on LSM (Litton Bionetics, Kensington, MD). To obtain activated $T$ cells, PBMC were cultured for three days in tissue culture flasks (Falcon Labware, Div. Becton, Dickinson, and Co., Oxnard, CA) at a density of $10^{6} / \mathrm{ml}$ in RPMI 1640 medium containing phytohemagglutinin (PHA; Burroughs Wellcome, Research Triangle Park, NC) at a final concentration of $1 \mu \mathrm{g} / \mathrm{ml}, 2 \mathrm{mM}$ glutamine, antibiotics, and $10 \%$ FCS. Cell lines (SB and HSB-2, provided by Dr. B. Haynes, Duke University, Durham, NC; Jurkat and HUT 78, provided by Dr. A. Altman, Scripps Clinic and Research Foundation, La Jolla, CA; and mouse EL-4) were cultured in RPMI 1640 medium containing 10\% FCS, glutamine, and antibiotics.

Special immunological reagents. Preparation and characterization of monospecific rabbit antibody to mouse heat-shock protein hsp90 were described previously (3). Q5/13, a DR $\beta$-chain framework monoclonal antibody, and Q1/28, a HLA class I framework monoclonal antibody (both active in Western blotting) were gifts of Dr. Leslie Walker, Scripps Clinic and Research Foundation. Horseradish-conjugated goat antibodies to human IgG and IgM (Cappel Laboratories, Cochranville, PA) and rabbit IgG (Bio-Rad Laboratories, Richmond, CA) were used in Western blotting experiments. Heat-aggregated IgG was prepared from Cohn fraction II (Sigma Chemical Co., St. Louis, MO) according to the technique of Dickler (13).

Preparation of $T$ cell detergent lysates and purified plasma membranes. This was performed as described in detail previously (14). Briefly, cells were incubated in lysis buffer (PBS, pH 7.4 containing $0.5 \%$ Nonidet P-40, $2 \mathrm{mM}$ phenylmethyl-sulfonyl fluoride, and 1 trypsin inhibitory unit/ml aprotinin) for $60 \mathrm{~min}$ on ice, followed by clearance of the lysates of nuclei (monitored by phase contrast microscopy) by centrifugation at $400 \mathrm{~g}$, and ultracentrifugation at $100,000 \mathrm{~g}$ to remove cytoskeletal components and unsolubilized membranes. Aliquots were kept frozen at $-70^{\circ} \mathrm{C}$ until use. Highly purified plasma membranes were isolated on discontinuous sucrose density gradients from lymphoblastoid cells disrupted with a cell disrupter (Stansted Fluid Power, Ltd., Essex, UK) according to the method of Crumpton and Snary (15). HLA class I and/or class II antigens, detected by Western blotting with Q1/28 and Q5/13 monoclonal antibodies, respectively, were enriched $>32$-fold in purified membrane preparations relative to whole $\mathrm{T}$ cell lysates. Protein concentrations of whole T cell lysates and purified membrane preparations were determined by a modified Lowry procedure using appropriate blanks (16). 
SDS-PAGE and Western blotting. Cell detergent lysates or membrane preparations were electrophoresed on $7.5 \%$ polyacrylamide slab gels under reducing or nonreducing conditions according to the technique of Laemmli (17). Proteins were electroeluted from the gels to nitrocellulose sheets for Western blot analysis (18), as described in detail previously (14). The nitrocellulose sheets were cut into 5-mm strips and incubated for $1-2 \mathrm{~h}$ at $25^{\circ} \mathrm{C}$ in quenching buffer $(20 \mathrm{mM}$ Tris- $\mathrm{HCl}, \mathrm{pH} 7.4,0.13 \mathrm{M} \mathrm{NaCl}$, containing 5\% nonfat dry milk), followed by a $1-\mathrm{h}$ incubation at $4^{\circ} \mathrm{C}$ with constant agitation in various dilutions of SLE patient serum or rabbit anti-hsp90. A standard 1:20 dilution of serum normalized to an IgG concentration of $10 \mathrm{mg} / \mathrm{ml}$ in Tris-buffered saline (TBS), pH 7.4, provided optimum sensitivity and minimum non-specific staining. Normal human serum, aggregated normal IgG, and normal rabbit serum were used as controls. After washing three times with TBS buffer containing $0.02 \%$ Tween 20 , strips were incubated for $1 \mathrm{~h}$ with appropriate peroxidase-conjugated antiimmunoglobulin reagents, rewashed, and developed for color with HRP color development reagent (Bio-Rad Laboratories). Protein standards (Bio-Rad) were used to calibrate molecular weights (19). For some experiments, lymphocytes were intrinsically labeled with $\left[{ }^{35} \mathrm{~S}\right]-$ methionine (Amersham Corp., Arlington Heights, IL) in methioninefree RPMI 1640/dialyzed FCS. Labeled proteins were analyzed by fluorography of SDS-polyacrylamide gel slabs.

Preclearance experiments. $75 \mu \mathrm{l}$ of rabbit anti-mouse hsp90 or normal rabbit serum were incubated with $100 \mu l$ of protein A-Sepharose 4B (Pharmacia Fine Chemicals, Piscataway, NJ) for $4 \mathrm{~h}$ at $4^{\circ} \mathrm{C}$ to prepare solid-phase antibody. The beads then were washed $3 \times$ with PBS and continuously rotated with $60 \mu \mathrm{l}$ of Jurkat cell lysate (protein concentration $=1 \mathrm{mg} / \mathrm{ml}$ ) at $4^{\circ} \mathrm{C}$ for $4 \mathrm{~h}$. The supernatant was recovered by centrifugation and used as substrate in SDS-PAGE and Western blotting.

\section{Results}

7 of 15 sera from patients with SLE contained IgG that reacted with a molecule of $M_{\mathrm{r}} 90,000$ on Western blots prepared from nonionic detergent lysates of resting or activated peripheral $T$ cells electrophoresed on SDS-polyacrylamide gels under reducing or nonreducing conditions. IgG staining of this band also was detected in sera from 2/6 patients with polymyositis, but not in sera from patients with rheumatoid arthritis $(n=10)$ or systemic sclerosis $(n=7)$. The $90-\mathrm{kD}$ target was expressed by $T$ cell lines of varying degrees of maturity and activation, by $B$ cells, and by a mouse T cell line, EL-4 (Fig. 1 a). Staining appeared to involve specific antibody interactions since normal human sera and heat-aggregated IgG in concentrations approximately twofold higher than that of SLE serum were consistently negative in this regard (data not shown).

Three lines of evidence established that the $90-\mathrm{kD}$ SLE autoantibody target was the heat-shock protein, hsp90. First, both proteins migrated together during SDS-PAGE (Figs. $1 a$ and $b$ ). Second, when rabbit anti-hsp90 was used to preclear lymphocyte detergent lysates, hsp90 and the SLE IgG-reactive band were eliminated in parallel (Fig. 2, lanes 4 and 6, respectively). Specificity of anti-hsp90 immunoabsorption in these experiments was confirmed by the failure of control immunoprecipitation with normal rabbit serum to remove this protein (odd-numbered lanes in Fig. 2), by the specific absorption by anti-hsp90 only of a 90,000 -D protein in amido black stained gels (Fig. 2, lane 2), and by the persistence in the anti-hsp90 precleared lysate of unrelated 57,000- and 34,000-D SLE antibody targets (Fig. 2, lane 6 ). Third, the $90-\mathrm{kD}$ protein exhibited the heat response characteristic of heat-shock proteins (Fig. 3). HSB-2 and HUT 78 cells were incubated at $37^{\circ} \mathrm{C}$ or at $45^{\circ} \mathrm{C}$, and labeled biosynthetically with $\left[{ }^{35} \mathrm{~S}\right]$ methionine either immediately, or after a $2-\mathrm{h}$ incubation at $37^{\circ} \mathrm{C}$ following the heat shock. Protein synthesis was decreased by the heat shock in cells labeled immediately, but in cells labeled $2 \mathrm{~h}$ later, uptake of $\left[{ }^{35} \mathrm{~S}\right]$ methionine was increased in previously defined (5) heat shock proteins of $M_{\mathrm{r}} 90,000,110,000$, and 72-73,000.

\section{Discussion}

This investigation delineates hsp90, a major intracellular heat-shock protein, as a common IgG autoantibody target in

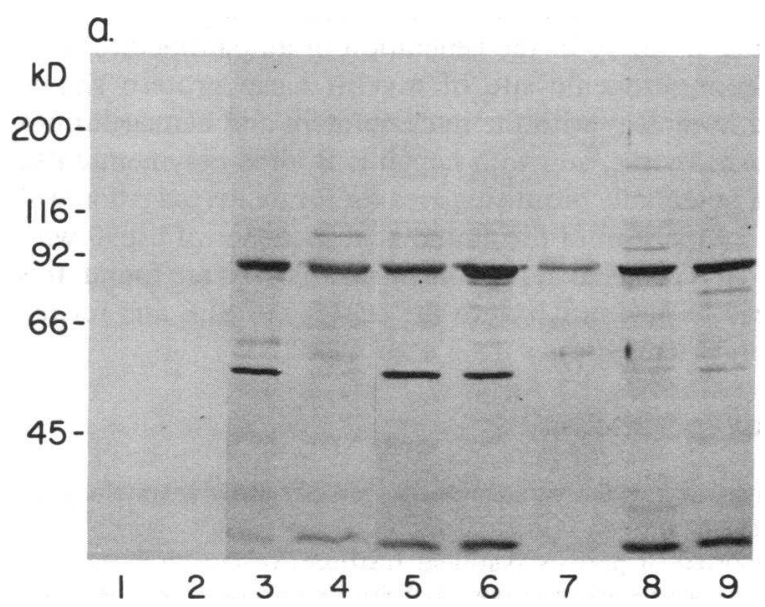

Figure 1. A 90-kD molecule widely expressed on cells of human and murine origin reacts with SLE IgG and rabbit antibody to the heatshock protein, hsp 90 . Nonidet $P-40$ cell lysates or purified plasma membranes were electrophoresed under reducing condition on $7.5 \%$ SDS-polyacrylamide gels. Proteins were electroeluted to nitrocellulose and examined for IgG antibody staining. In $a$, blots were incubated with serum from two normal individuals (lanes 1 and 2) or from SLE patient $\mathrm{Ne}$ (lanes 3-9); in $b$, blots were incubated with rabbit antibody to hsp90 (lanes 1-8). Antigen substrates in $a$ included:

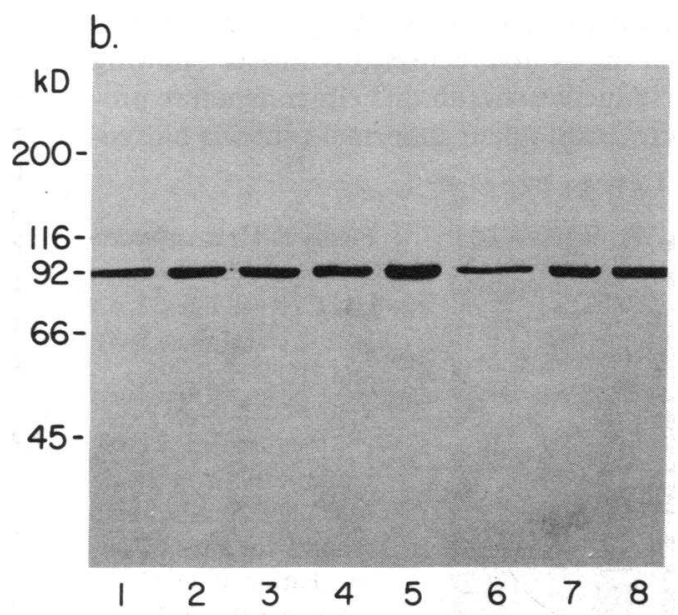

PHA-activated human peripheral T cell detergent lysate (lanes 1-3), HSB-2 lysate (lane 4), Jurkat lysate (lane 5), HUT 78 lysate (lane 6), purified HUT 78 membranes (lane 7), mouse EL-4 lysate (lane 8), and SB lysate (lane 9). Antigen substrates in $b$ included: resting peripheral T cell lysate (lane 1), PHA-activated peripheral T cell lysate (lane 2), HSB-2 lysate (lane 3), Jurkat lysate (lane 4), HUT 78 lysate (lane 5), purified HUT 78 membranes (lane 6), mouse EL-4 lysate (lane 7), and SB lysate (lane 8). 


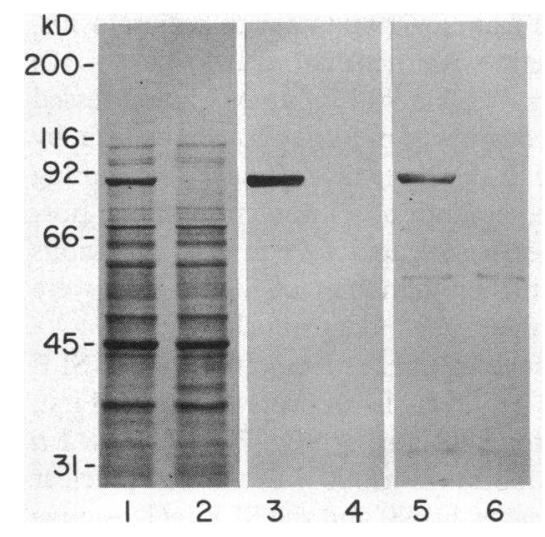

Figure 2. Immunoabsorption of the $90-\mathrm{kD}$ SLE IgG target with rabbit anti-hsp90. Solidphase immunoabsorption of Jurkat cell lysates was performed with complexes of protein A-Sepharose 4B and normal rabbit IgG (control, lanes 1, 3, and 5) or rabbit anti-hsp90 (lanes 2, 4, and 6). A major cellular protein of $M_{\mathrm{r}} 90,000$ is specifically removed by ab-

sorption with anti-hsp90, but not with normal rabbit IgG (amido black-stained gels, lanes 1 and 2). Anti-hsp90 staining (lanes 3 and 4 ) and SLE IgG staining (lanes 5 and 6 ) of a $90-\mathrm{kD}$ antigen is specifcally absorbed with anti-hsp 90 .

SLE. Autoantibodies against hsp 90 were encountered in $<10 \%$ of a panel of 23 sera from patients with non-SLE systemic rheumatic diseases, and were not observed in normal human sera. These data, albeit limited, raise the possibility that anti-hsp 90 autoantibodies may be relatively specific for SLE.

In an earlier report from this laboratory (14), the $90 \mathrm{kD}$ protein now identified as hsp 90 was thought to be a lymphocyte surface membrane target of antilymphocyte autoantibodies in SLE because it was detected in purified plasma membrane preparations. Copurification of hsp 90 with plasma membranes was confirmed in the present investigation, but by immunofluorescence, this antigen clearly is intracytoplasmic, with staining along the periphery of the cell adjacent to the plasma membrane (3). Taken together, these observations suggest that hsp90 is strongly linked to the inner surface of the plasmalemma.

Heat-shock proteins are ubiquitous, highly conserved molecules that, by definition, exhibit increased synthesis following exposure of cells to inductive stimuli that either denature proteins or cause cells to accumulate abnormal proteins biosyn-

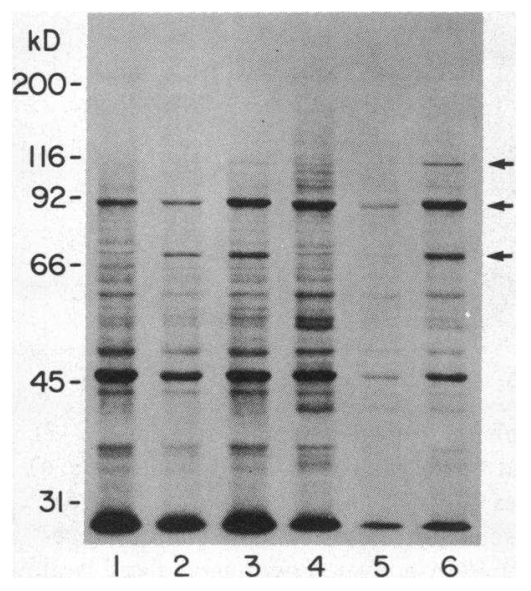

Figure 3. Heat shock response of HSB-2 and HUT 78 cell lines. HSB-2 cells (lanes 1-3) and HUT 78 (lanes 4-6) were labeled with $\left[{ }^{35}\right.$ S]methionine immediately after heat shock $\left(45^{\circ} \mathrm{C}\right.$ for $10 \mathrm{~min}$; lanes 2 and 5 ) or after a $2-\mathrm{h}$ incubation at $37^{\circ} \mathrm{C}$ after heat shock (lanes 3 and 6). Lanes 1 and 4 contain lysates incubated at $37^{\circ} \mathrm{C}$ for $2 \mathrm{~h}$ without heat shock as a control. Aliquots of cell lysates containing 7.5

$\mu \mathrm{g}$ protein in each lane were electrophoresed on a SDS polyacrylamide gel (7.5\% reducing conditions) and the gel was autofluorographed. thetically, e.g., supraphysiologic temperatures, certain drugs, transition series metals, and various amino acid analogues (5). In addition to a presumed physiologic role for heat-shock proteins as a group in the general response of the cell to "stress," i.e., generation of thermotolerance, cell homeostasis, or thermoregulation, several recent observations suggest that hsp 90 has important, if obscure, functions in the biology of the cell. Thus, hsp 90 has been shown to exist as a complex with steroid receptors (8), and with several sarcoma virus-encoded transforming peptides $(6,7)$, and binds to F-actin in a calmodulin regulated, $\mathrm{Ca}^{2+}$-dependent manner $(3,4)$. Certain data suggest that hsp90 and other heat-shock proteins also act in the transition of proliferating cells to $G_{0}$ or in maintaining cells in the resting state (20). Whether autoantibodies to heat-shock proteins contribute to the hormonal diathesis in SLE (21), to abnormal capping (22), or to endogenous lymphocyte activation $(23,24)$ in this disorder is purely conjectural. Nonetheless, the potential for in vivo relevance in this regard is provided by data of Okudaira et al., who demonstrated that certain IgG autoantibodies in SLE have the capacity to localize in the cytoplasm of viable lymphocytes (25).

Also of importance are the clues that autoantibodies such as anti-hsp90 offer with respect to putative microbial triggers of autoimmunity. Indeed, an immunodominant peptide of Schistosoma mansoni has amino acid sequence homology with the heat-shock protein, hsp70, and may be responsible for autoantibodies to hsp70 in individuals infected with this organism (10). A large body of additional evidence supports the concept of molecular mimicry (epitope homology) as a basis for the generation of autoantibodies following infection with microbial "triggering agents" (reviewed in 9). For example, $\sim 4 \%$ of over 600 monoclonal antibodies generated against a variety of DNA and RNA viruses cross-react with uninfected host determinants (26). Autoantibodies developing in the course of infectious mononucleosis are directed to epitopes shared by multiple self antigens and the glycine-alanine repeat region of Epstein Barr nuclear antigen-1 (27). Analyses of virus and host peptide sequences further supports a major role for molecular mimicry in the generation of autoantibodies, e.g., the encephalitogenic site of myelin basic protein shows marked homology with the nucleoprotein and hemagglutinin of influenza virus, and with hepatitis B virus polymerase (9). Thus, a potentially promising area for future investigation will be the comparison of the amino acid sequence of hsp 90 with that of viral proteins. If homologous sequences are found, this may lead to new insight into the etiology of SLE and related autoimmune diseases.

\section{Acknowledgments}

The expert technical assistance of Ms. Melody Shaw is gratefully acknowledged.

Supported in part by National Institutes of Health grant RO1 AM-30863, a NIH Multipurpose Arthritis Center grant, and a Biomedical Research Center grant from the Arthritis Foundation.

\section{References}

1. Tan, E. M. 1982. Autoantibodies to nuclear antigens (ANA): their immunobiology and medicine. Adv. Immunol. 33:167-240.

2. Winfield, J. B. 1985. Anti-lymphocyte antibodies in systemic lupus erythematosus. Clin. Rheum. Dis. 11:523-549.

3. Koyasu, S., E. Nishida, T. Kadowski, F. Matsuzaki, K. Iida, F. 
Harada, M. Kasuga, H. Sakai, and I. Yahara. 1986. Two mammalian heat shock proteins, HSP90 and HSP100, are actin-binding proteins. Proc. Natl. Acad. Sci. USA. 83:8054-8058.

4. Nishida, E., S. Koyasu, H. Sakai, and I. Yahara. 1986. Calmodulin-regulated binding of the $90-\mathrm{kDa}$ heat shock protein to actin filaments. J. Biol. Chem. 261:16033-16036.

5. Schlesinger, M. J., M. Ashburner, and A. Tissieres. 1982. Heat Shock from Bacteria to Man. Cold Spring Harbor Laboratory, Cold Spring Harbor, New York.

6. Opperman, H., W. Levinson, and J. M. Bishop. 1981. A cellular protein that associates with a transforming protein of Rous sarcoma virus is also a heat-shock protein. Proc. Natl. Acad. Sci. USA. 78:1067-1071.

7. Adkins, B., T. Hunter, and B. M. Sefton. 1982. The transforming proteins of PRCII virus and Rous satcoma virus form a complex with the same two cellular phosphoproteins. J. Virol. 43:448-455.

8. Schuh, S., W. Yonemoto, J. Brugge, V. J. Bauer, R. M. Riehl, W. P. Sullivan, and D. O. Toft. 1985. A 90,000-Dalton binding protein common to both steroid receptors and the Rous sarcoma virus transforming protein, pp60 $0^{\text {v-src }} \mathrm{J}$. Biol. Chem. 260:14292-14296.

9. Oldstone, M. B. A., and A. L. Notkins. 1986. Molecular mimicry. In Concepts in Viral Pathogenesis. Vol. II. M. B. A. Oldstone and A. L. Notkins, editors. Springer-Verlag, New York. 195-202.

10. Hedstrom, R., J. Culpepper, R. A. Harrison, N. Agabian, and G. Newport. 1987. A major immunogen in Schistosoma mansoni infections is homologous to the heat-shock protein hsp90. J. Exp. Med. 165:1430-1435.

11. Tan, E. M., A. S. Cohen, J. F. Fries, A. T. Masi, D. J. McShane, N. F. Rothfield, J. G. Schaller, N. Talal, and R. J. Winchester. 1982. The 1982 revised criteria for the classification of systemic lupus erythematosus. Arthritis Rheum. 25:1271-1277.

12. Morimoto, C., E. L. Reinherz, J. A. Distaso, A. D. Steinberg, and S. F. Schlossman. 1984. Relationship between systemic lupus erythematosus $T$ cell subsets, anti-T cell antibodies, and $T$ cell functions. J. Clin. Invest. 73:689-700.

13. Dickler, H. B. 1974. Studies of the human lymphocyte receptor for heat-aggregated or antigen-complexed immunoglobulin. J. Exp. Med. 140:508-522.

14. Minota, S., and J. B. Winfield. 1987. IgG anti-lymphocyte antibodies in systemic lupus erythematosus react with surface molecules shared by peripheral $\mathrm{T}$ cells and a primitive $\mathrm{T}$ cell line. J. Immunol. 138:1750-1756.

15. Crumpton, M. J., and D. Snary. 1974. Preparation and properties of lymphocyte plasma membranes. In Contemporary Topics in
Molecular Immunology, Vol. 3. G. L. Auda, editor. Plenum Press, New York. 27-55.

16. Cadman, E., J. R. Bostwick, and J. Eichberg. 1979. Determination of protein by modified Lowry procedure in the presence of some commonly used detergents. Anal. Biochem. 96:21-23.

17. Laemmli, U. K. 1970. Cleavage of structural proteins during the assembly of the head of bacteriophage T4. Nature (Lond.). 277:680-685.

18. Towbin, H., T. Staehelin, and J. Gordon. 1979. Electrophoretic transfer of proteins from polyacrylamide gels to nitrocellulose sheets: procedure and source applications. Proc. Natl. Acad. Sci. USA. 76:4350-4354.

19. Shapiro, A. L., E. Viñuela, and J. V. Maizel. 1967. Molecular weight estimation of polypeptide chains by electrophoresis in SDSpolyacrylamide gels. Biochem. Biophys. Res. Commun. 28:815-820.

20. Iida, H., and I. Yahara. 1984. Durable synthesis of high molecular weight heat shock proteins in $\mathrm{G}_{0}$ cells of the yeast and other eucaryotes. J. Clin. Biol. 99:199-207.

21. Lahita, R. G. 1987. Sex and age in systemic lupus erythematosus. In Systemic Lupus Erythematosus. R. G. Lahita, editor. John Wiley \& Sons, New York, 523-539.

22. Kammer, G. M. 1983. Impaired T cell capping and receptor regeneration in active systemic lupus erythematosus. Evidence for a disorder intrinsic to the T lymphocyte. J. Clin. Invest. 72:1686-1697.

23. Jasin, H. E., and M. Ziff. 1975. Immunoglobulin synthesis by peripheral blood cells in systemic lupus erythematosus. Arthritis Rheum. 18:219-228.

24. Yu, D. T. Y., R. J. Winchester, S. M. Fu, A. Gibofsky, H. S. Ko, and H. G. Kunkel. 1980. Peripheral blood Ia-positive T cells: Increases in certain diseases and after immunization. J. Exp. Med. 151:91-100.

25. Okudaira, K., R. P. Searles, K. Tanimoto, Y. Horiuchi, and R. C. Jr. Williams. 1982. T lymphocyte interaction with immunoglobulin $\mathrm{G}$ antibody in systemic lupus erythematosus. J. Clin. Invest. 69:1026-1038.

26. Srinivasappa, J., J. Saegusa, B. S. Prabhakar, M. K. Gentry, M. J. Buchmeier, T. J. Wiktor, H. Koprowski, M. B. A. Oldstone, and A. L. Notkins. 1986. Molecular mimicry: frequency of reactivity of monoclonal antiviral antibodies with normal tissues. J. Virol. 57:397401.

27. Rhodes, G., H. Rumpold, P. Kurki, K. Patrick, D. Carson, and J. Vaughn. 1987. Autoantibodies in infectious mononucleosis have specificity for the glycine-alanine repeating region of the Epstein-Barr virus nuclear antigen. J. Exp. Med. 165:1026-1040. 